\title{
In situ measurements of Antarctic snow compaction compared with predictions of models
}

\author{
Robert J. Arthern, ${ }^{1}$ David G. Vaughan, ${ }^{1}$ Andrew M. Rankin, ${ }^{1}$ Robert Mulvaney, ${ }^{1}$ \\ and Elizabeth R. Thomas ${ }^{1}$ \\ Received 11 March 2009; revised 24 February 2010; accepted 30 March 2010; published 29 July 2010.
}

[1] We describe in situ measurements of the compaction of Antarctic snow. At three different sites in Antarctica, the rate of compaction was measured hourly, over various depth intervals, for up to two years. These measurements show that compaction at each of the sites occurs through slow, viscous deformation of the snowpack, with no significant contribution from sudden collapse of weak layers. The measured rates of compaction at the coldest site exhibit a strong seasonality, consistent with a temperature-dependent sintering mechanism having activation energy of $70 \mathrm{~kJ} \mathrm{~mol}^{-1}$. At the two warmer sites, activation energies of 80 and $120 \mathrm{~kJ} \mathrm{~mol}^{-1}$ provide slightly better agreement with the observations. Published models of snow compaction underestimate the temperature sensitivity. A good match to our observations is provided by a semi-empirical model, based on rate equations for lattice-diffusion (Nabarro-Herring) creep of material around pores, combined with normal grain growth. This model also provides a theoretical basis for a widely used empirical model of snow compaction. The rate coefficient for lattice-diffusion inferred from our measurements is considerably higher than published values, however, and other creep mechanisms cannot be ruled out.

Citation: Arthern, R. J., D. G. Vaughan, A. M. Rankin, R. Mulvaney, and E. R. Thomas (2010), In situ measurements of Antarctic snow compaction compared with predictions of models, J. Geophys. Res., 115, F03011, doi:10.1029/2009JF001306.

\section{Introduction}

[2] In the porous upper layers of the ice sheets that cover Greenland and Antarctica the density can fluctuate over time. This can introduce errors when satellite altimeters are used to assess the contribution made by the ice sheets to global sea level change [Braithwaite et al., 1994; Arthern and Wingham, 1998; Zwally et al., 2005; Helsen et al., 2008]; it can also affect the interpretation of samples of the past atmosphere trapped in ice cores [Barnola et al., 1991]. In both cases, corrections are applied to account for density changes, and these rely on models of the rate of snow compaction [Barnola et al., 1991; Arthern and Wingham, 1998; Wingham, 2000; McConnell et al., 2000; Zwally and Li, 2002; Li and Zwally, 2004; Zwally et al., 2005; Helsen et al., 2008; Reeh, 2008]. Uncertainty in these models limits the accuracy of dates applied to atmospheric samples from ice cores, and of measured changes in the mass of the ice sheets. More generally, theories of sintering have wider industrial applications [e.g., Wilkinson, 1988]. To test the available models, we performed experiments to measure the rate of compaction of Antarctic snow.

[3] In regions of Antarctica and Greenland that are too cold for summer melting, surface snow is buried and crushed by subsequent snowfall. The compacted snow is slowly trans-

\footnotetext{
${ }^{1}$ British Antarctic Survey, Cambridge, UK.
}

Copyright 2010 by the American Geophysical Union. 0148-0227/10/2009JF001306 formed into glacier ice, via an intermediate state called "firn." During this transformation the firn undergoes a slow burial and compression under ever increasing load. Air is squeezed out, and density increases with depth. Near the surface (after some drifting, disintegration and initial settling of snow crystals) the volume ratio is typically one part ice to two parts air. Centuries or millennia can pass before $90 \%$ ice density is reached. At such a high density, the remaining air becomes trapped as isolated bubbles. By that time the firn may have been buried to a depth of a hundred meters or so.

[4] The rate at which a parcel of snow compacts under a given stress depends upon its rheology. This is partly controlled by the viscosity of ice, but also by the arrangement of snow grains. Stresses are concentrated at grain contacts, where various sintering processes cause deformation, leading to densification. Reviews by Maeno and Ebinuma [1983], Paterson [1994], Colbeck [1998], and Blackford [2007] describe the process of firn compaction in more detail.

[5] Samples taken from ice cores and snowpits can reveal the profile of density $\rho$ as a function of depth $z$. Many investigations have parameterized the density-depth profile $\rho(z)$ in terms of local climatological parameters, such as mean annual temperature $T_{\mathrm{av}}$, mass accumulation rate $\dot{b}$, and the deposition density at the surface $\rho_{s}$ [e.g., Bader, 1960, 1962; Kojima, 1964; Herron and Langway, 1980; Alley, 1987; Barnola et al., 1991; Spencer et al., 2001].

[6] By itself, the density-depth profile $\rho(z)$ provides no information about the rate of compaction. To estimate compaction rates it is often assumed that there are no sources or 


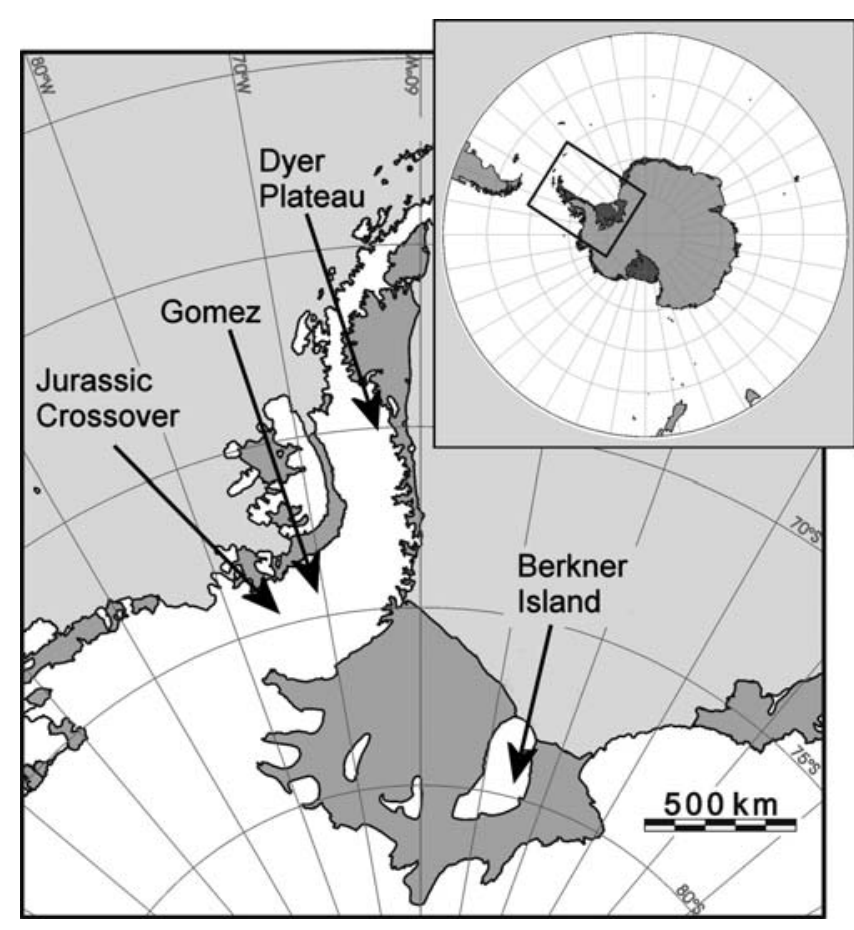

Figure 1. Location map showing sites mentioned in text.

sinks of mass within the snow, and that the density-depth profile equilibrates to an unchanging 'steady state'. From mass conservation, the vertical velocity of a parcel relative to the surface is then $v(z) \approx \dot{b} / \rho(z)$, sometimes referred to as 'Sorge's Law' [Bader, 1960, 1962]. Differentiation with respect to depth provides an estimate for the strain rate of compaction: $\dot{\epsilon} \equiv \partial v / \partial z \approx-(\partial \rho / \partial z) \dot{b} / \rho^{2}$. This expression allows compaction rates to be estimated from quantities that can be measured from an ice core or snow-pit [Bader, 1960, 1962; Kojima, 1964; Herron and Langway, 1980].

[7] There is no universally accepted expression for snow rheology that reconciles field observations, laboratory measurements, and sintering theories, although many have been proposed in the literature [e.g., Bader, 1960, 1962; Kojima, 1964; Herron and Langway, 1980; Alley, 1987; Barnola et al., 1991; Gray and Morland, 1995; Spencer et al., 2001; Li and Zwally, 2004; Helsen et al., 2008]. Some of these are purely empirical; others are based upon sintering theories, with rate coefficients selected to match laboratory experiments, or density-depth profiles recovered from ice cores. Generally the models agree fairly well with ice core data, but each predicts different sensitivity to important physical conditions, such as temperature, deposition density, accumulation rate, grain-size, and the weight of overlying snow.

[8] Herron and Langway [1980] used the assumption of steady state compaction, and density-depth profiles from many different sites to derive a widely used empirical parameterization of firn rheology. However, the functional form and temperature sensitivity of this parameterization differs from alternatives that have their origin in the rate equations used to model sintering mechanisms [Coble, 1970; Maeno and Ebinuma, 1983; Alley, 1987; Wilkinson, 1988; Colbeck, 1998]. This leaves open the possibility that the Herron and Langway [1980] model may not describe dynamical variations in density as accurately as it describes steady state compaction. Alternative models, broadly based upon the Herron and Langway [1980] parameterization, have employed different formulations for the sensitivity to temperature [Li and Zwally, 2004; Helsen et al., 2008].

[9] Changes in weather and climate can cause temperature, accumulation rate, and depositional density to vary. Consequently, and in violation of Sorge's Law, the density profile $\rho(z, t)$ will fluctuate with time $t$. As outlined above, knowledge of these fluctuations is needed to study the Earth's climate, and to estimate the contribution of ice sheets to sea level rise. There are many alternative models of snow compaction to choose from, but to discriminate among them there are surprisingly few in situ observations of how the rate of Antarctic snow compaction varies from month-to-month or year-to-year. Surface height variations relative to snowstakes, combined with density observations from shallow pits, reveal evidence for enhanced compaction in the summer months [Kotlyakov, 1961; Dibb and Fahnestock, 2004]. However, to our knowledge, compaction rates have not been measured continuously by direct instrumentation of the snowpack.

[10] To investigate the temporal evolution of density we performed field experiments to obtain direct in situ measurements of the rate of snow compaction. As well as providing time series for the validation of models, we develop some explanatory investigations of the key sensitivities and rate constants. Initially, we concentrate upon models that are based upon the empirical Herron and Langway [1980] parameterization, because of its simplicity, and its widespread use in the interpretation of gases trapped in ice cores, and elevation changes measured by satellites. Zwally and $\mathrm{Li}$ [2002] have suggested that compaction is much more sensitive to temperature than earlier studies [e.g. Herron and Langway, 1980; Alley, 1987; Arthern and Wingham, 1998]. For this reason, we pay particular attention to characterizing the temperature sensitivity.

[11] In Section 2 we describe experimental methods. In Section 3 we compare results with the predictions of models from the literature. In Section 4 we interpret those results in the context of physical mechanisms of snow compaction. Section 5 summarizes our findings.

\section{Methods}

[12] Between January 2004 and February 2007, strainmeters were installed in the Antarctic snowpack, at locations shown in Figure 1. The Jurassic and Dyer Plateau sites lie on the ice divide that forms the spine of the Antarctic Peninsula, while Gomez lies on its western flank. The Gomez and Jurassic sites are close to nunataks of the same name, and the Berkner Island site lies atop the southern dome of that ice rise. All sites except Jurassic were placed close to ice core drilling sites, and all are free from melt, even in summer. Similar equipment was also installed on the Wormold Glacier near to Rothera Station, which does experience melt, but in this paper we consider just the sites in the dry snow zone.

[13] The instruments took hourly recordings of vertical strain, using an automatic sensor that detected changes in the length of a bowstring connecting top and bottom of a borehole (Figure 2). The approach is an automated version of the 'coffee-can' method for measuring thickness changes, described by Hamilton et al. [1998]. 


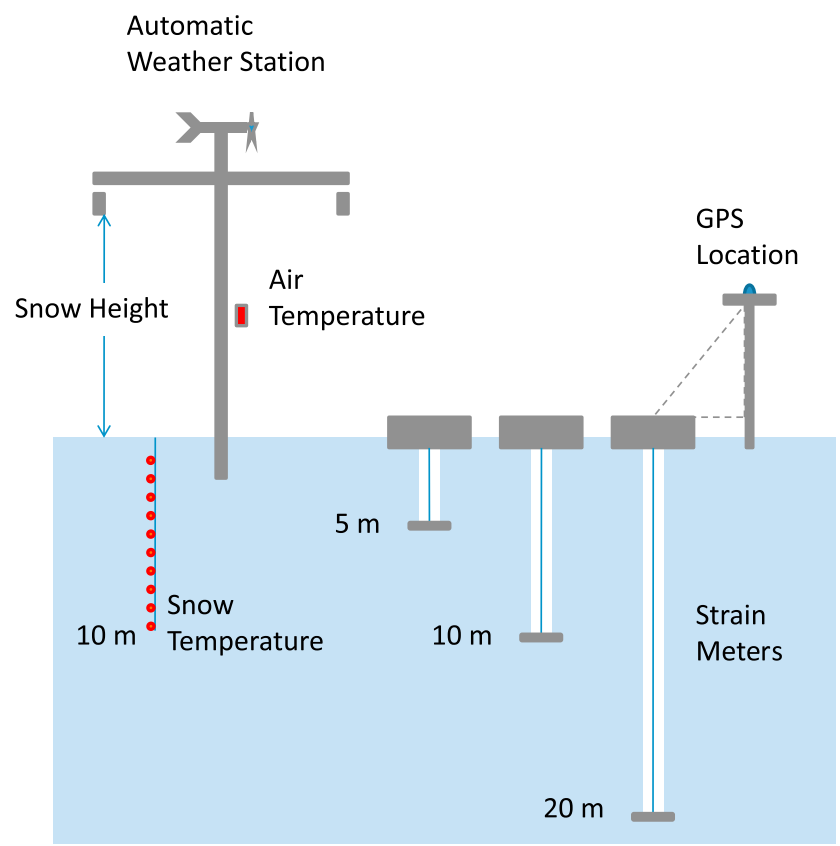

Figure 2. Equipment deployed at each site.

[14] The bowstring was made from a composite of Ultra High Molecular Weight Polyethylene (Dyneema) and Liquid Crystal Polymer (Vectran) to minimize any change in its length from elastic, creep or thermal effects. The attachment point at the bottom of the borehole was a length of steel bar drilled through with an eyelet connected to the bowstring. The bar was heated in a flask of hot water, then lowered down the borehole and frozen in place at the bottom. Subsequent introduction of ice-chippings and a small amount of hot water further cemented it in place. To minimize any tendency of the steel bar to move relative to the surrounding snow, its weight was selected to approximately compensate for tension within the bowstring.

[15] At the top of the borehole, a position transducer (Ametek, P50-A) kept the bowstring under tension and recorded the amount of slack taken up as compaction of the surrounding snow proceeded. The position transducer operated as a potentiometer, recording the extension and retraction of a spring-tightened sensor cable to sub-millimeter precision. It was mounted in an aluminum case to protect it from weather, and from the weight of snowfall during burial.

[16] Boreholes were approximately $10 \mathrm{~cm}$ in diameter, and appeared sufficiently straight to avoid contact between the bowstring and the sides, although the full depth was not observed directly. Upon deployment the case was placed directly over the borehole, with the bowstring passing through a small hole in its floor. The bowstring was clipped onto the extended sensor cable, and pulleys within the case allowed the sensor cable to retract, so that slack could be taken up and measured as compaction proceeded. The pulleys and position transducer were mounted on a rigid aluminum frame inside the case, to resist deformation during burial (the arrangement is shown in Figure 3).

[17] At each site, three separate strain recording systems were installed, with steel bars placed at depths of five, 10, and 20 meters below the surface, each in a separate borehole.
Output from the three position sensors was recorded by a data-logger (Campbell, CR10X) powered by a 100Ah lead acid battery. The loggers and batteries were housed in separate fibreglass enclosures (not shown in Figure 3), with connecting cables running to each of the three strainmeters.

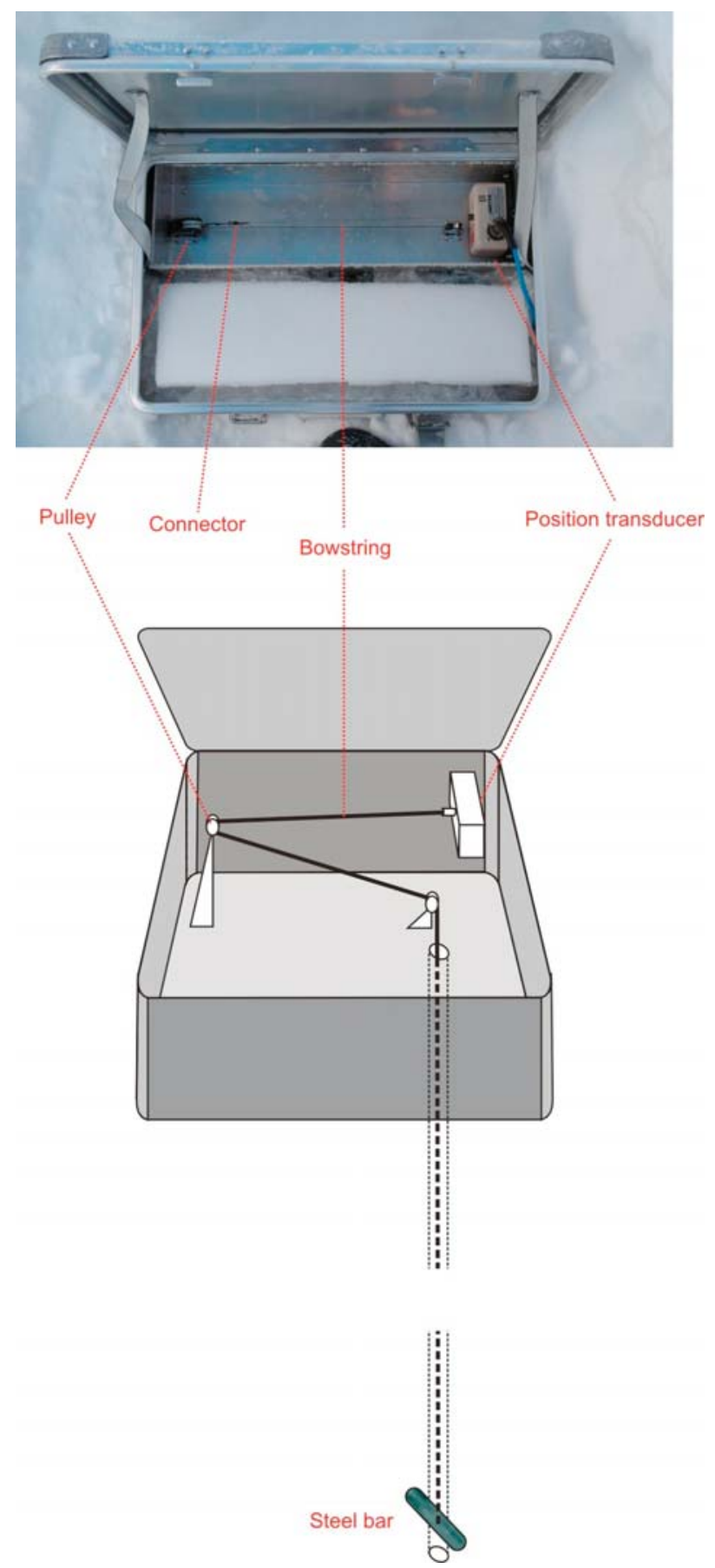

Figure 3. The arrangement of pulleys and position sensor within the aluminum case. The borehole lies directly beneath the right-hand pulley. The photo was taken upon recovery of the equipment. The attachment point between the bowstring and sensor wire is visible, and has just passed around the left-hand pulley. 
Table 1. Climatic Parameters for the Four Study Sites ${ }^{\mathrm{a}}$

\begin{tabular}{lccc}
\hline \multicolumn{1}{c}{ Site } & Latitude, Longitude & Mean Annual Temperature $T_{\text {av }}(\mathrm{K})$ & Accumulation Rate $\dot{b}\left(\mathrm{~kg} \mathrm{~m}^{-2} \mathrm{a}^{-1}\right)$ \\
\hline Jurassic & $-74.43^{\circ} \mathrm{N},-74.43^{\circ} \mathrm{E}$ & $252.5 \pm 0.1$ & $950 \pm 160$ \\
Gomez & $-74.00^{\circ} \mathrm{N},-70.61^{\circ} \mathrm{E}$ & $256.6 \pm 0.1$ & $1040 \pm 160$ \\
Berkner Island & $-79.57^{\circ} \mathrm{N},-45.79^{\circ} \mathrm{E}$ & $247.4 \pm 0.2$ & $130 \pm 40$ \\
Dyer Plateau & $-70.67^{\circ} \mathrm{N},-64.87^{\circ} \mathrm{E}$ & $252.8 \pm 0.1$ & $680 \pm 120$ \\
\hline
\end{tabular}

\footnotetext{
${ }^{\mathrm{a}}$ Mean annual temperatures were estimated from the average snow temperature at $10 \mathrm{~m}$ depth. Accumulation rates were estimated from shallow ice cores from Jurassic and Gomez, and Dyer Plateau Sites, and from Mulvaney et al. [2002] for Berkner Island. The standard deviation of seasonal fluctuations in $10 \mathrm{~m}$ temperature, and of interannual fluctuations in accumulation rate are also listed.
}

The battery lasted two years at the Gomez site, around seven months at the Jurassic site. At the Berkner Island site, two years of data were recovered, with the battery changed after one year. Data were stored on site until recovery of the equipment.

[18] We performed a number of checks. We maintained an eight-meter length of bowstring in a loft-space under the same tension used in the field experiments, and recorded the change in its length using the position transducer. After an initial extension of approximately $3 \mathrm{~mm}$, negligible rate of creep was observed $\left(<0.01 \mathrm{~mm}^{-1 a y}{ }^{-1}\right.$ over 18 days $)$. Temperature varied in the range $22-30^{\circ} \mathrm{C}$ during this test, but any strain from thermal effects was less than $0.2 \mathrm{~mm}$. We assessed the temperature-dependent bias in the assembled system of position transducers and loggers by moving them from an ambient temperature of $22^{\circ} \mathrm{C}$ into a cold-room at $-25^{\circ} \mathrm{C}$, allowing all equipment to equilibrate at the new temperature: recorded positions changed by less than $3 \mathrm{~mm}$ across the operating range. We checked the calibration of the position transducers during deployment, by recording the output voltage with the sensor wire fully retracted, fully extended, and at an intermediate position (the white pulley shown in Figure 3). We also performed physical measurements of the remaining length of travel, during deployment and recovery of the equipment, to guard against failure of the automatic logging system.

[19] Several auxiliary measurements were made at each site to supply initial conditions and boundary conditions for modeling the rate of snow compaction. Hourly temperatures at various depths within the upper ten meters of the snowpack were measured using a chain of thermistors, and stored on a second data-logger. An automatic weather station (AWS) provided hourly meteorological measurements (airtemperature, humidity, wind speed and direction). The AWS mast was guyed for stability, and fitted with two Campbell SR50 sonic ranging devices, mounted from a cross-mast. These monitored the arrival of snow at the site, logged hourly by the AWS unit. The weather station mast was $5 \mathrm{~m}$ high, with approximately $4.5 \mathrm{~m}$ above the surface at time of installation. At each location, the ice core from the twenty meter borehole was analyzed for density at approximately ten-centimeter depth resolution. Samples of meltwater from each core section were recovered from the field and analyzed using a Dionex ICS-2500 ion chromatograph. The annual accumulation record for each core was derived using the summer-summer maxima of two seasonally varying anions, one from methanesulphonic acid (MSA; $\left.\mathrm{CH}_{3} \mathrm{SO}_{3} \mathrm{H}\right)$ and sulphate $\left(\mathrm{SO}_{4}^{2}-\right)$, to provide the accumulation at the site prior to installation of the equipment. At the Berkner Island site, accumulation rate and densities from a pre-existing ice core were used [Gerland et al., 1999; Mulvaney et al., 2002].
[20] The strainmeters recorded vertical separation between snow-layers at either end of their respective boreholes. To tie this relative motion into geocentric coordinates, the precise location was determined at the start and end of the occupation using dual frequency global positioning system (GPS) recorders. The position of the snow surface, and of reference marks on the aluminum cases that contained the strain sensors, were surveyed using tape measures and trigonometric triangulation, to locate them relative to the GPS antenna. This local surveying was performed at installation and at recovery. The location of the AWS mast, and of the thermistor string, were surveyed relative to the GPS antenna in the same way. To estimate the component of the vertical motion due to downslope flow, the local slope was measured by differential GPS survey between the central location and three outlying sites, arranged in an equilateral triangle, each about one kilometer distant from the central site. Although not described further here these data will eventually allow pointestimates of the change in mass of ice per unit area [cf. Hamilton et al., 1998].

\section{Results}

[21] The climatic parameters recovered from the ice cores, and the automatic weather stations, are shown in Table 1.

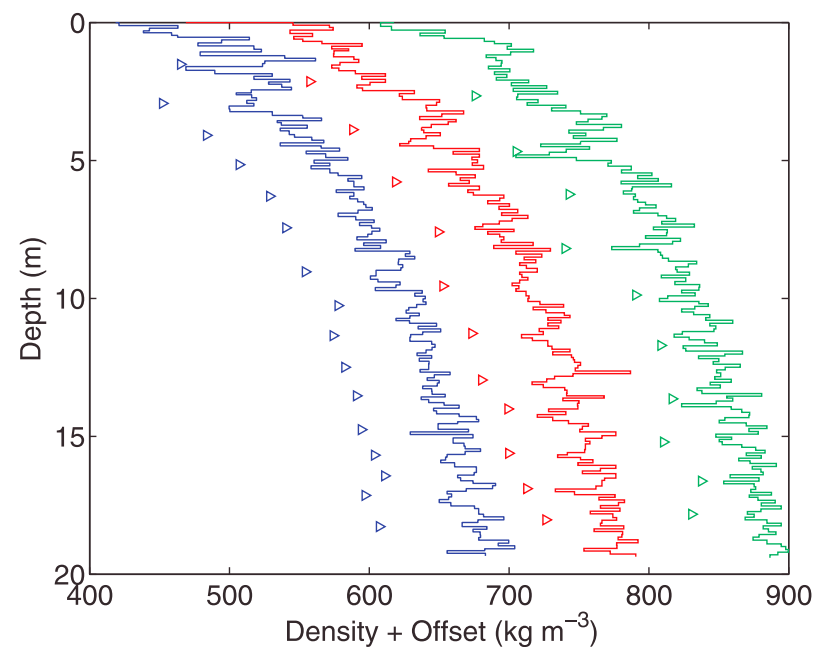

Figure 4. Densities from shallow ice cores: Dyer Plateau (blue); Jurassic (red, offset to the right by $100 \mathrm{~kg} \mathrm{~m}^{-3}$ ); Gomez (green, offset to the right by $200 \mathrm{~kg} \mathrm{~m}^{-3}$ ). Arrows indicate summer horizons identified from the concentration of two seasonally varying anions. For Berkner Island, accumulation rate and densities from a pre-existing ice core were used [Gerland et al., 1999; Mulvaney et al., 2002]. 

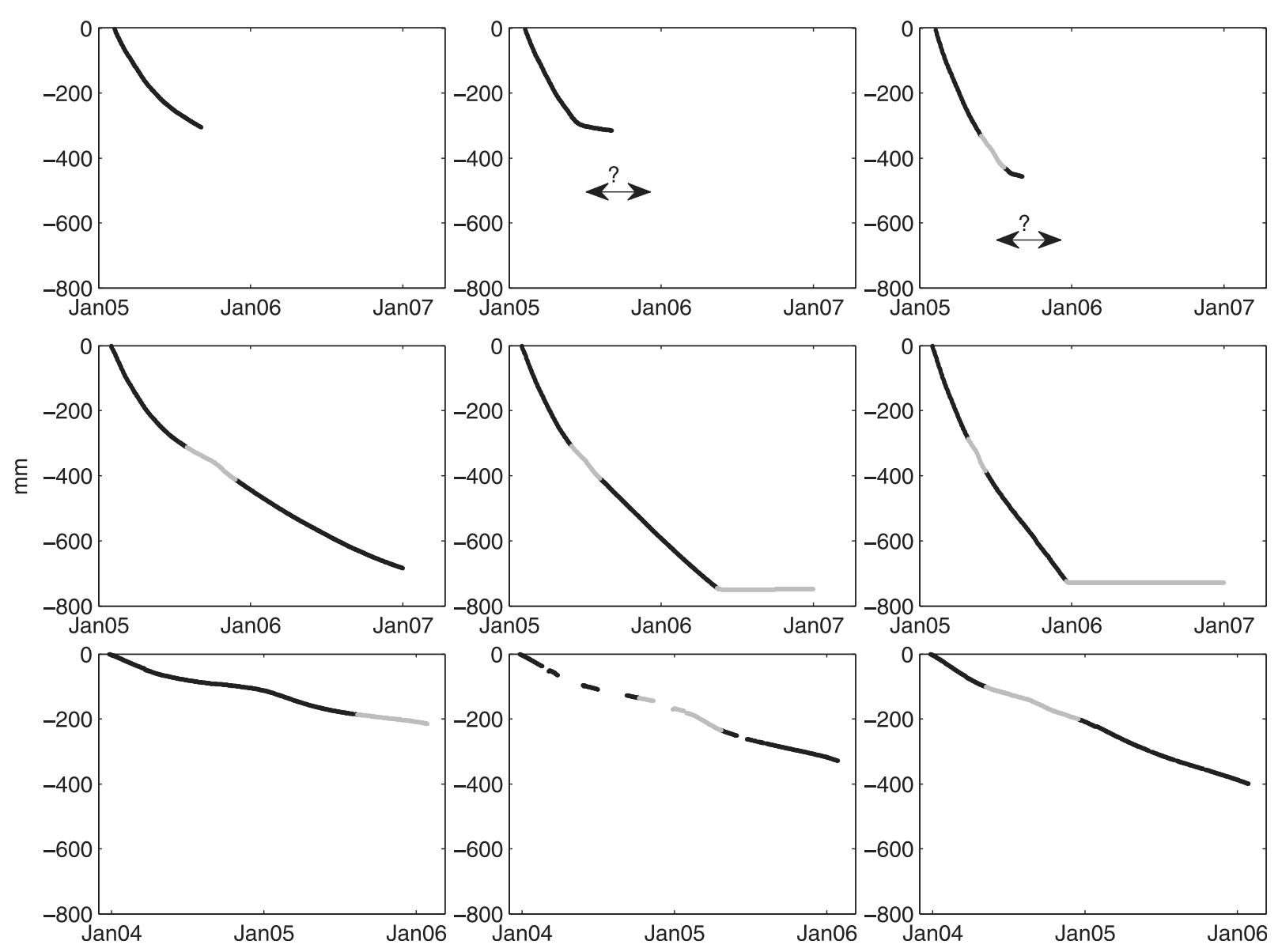

Figure 5. Total compaction in $\mathrm{mm}$ for different depth ranges: (left) $0-5 \mathrm{~m}$, (middle) $0-10 \mathrm{~m}$, and (right) 0 $20 \mathrm{~m}$, from three sites: (top) Jurassic, (middle) Gomez, and (bottom) Berkner Island. Dates are in monthyear format (e.g., Jan04 is January 2004). Data collected as the attachment point passed around the pulley, or reached the end of travel, are less reliable and are shown in gray. At the Jurassic site, two sensors seized during the experiment are indicated by question marks.

Figure 4 shows density profiles from the shallow ice cores; Jurassic and Gomez densities are offset by 100 and $200 \mathrm{~kg}$ $\mathrm{m}^{-3}$ respectively for clarity of display. Figure 5 shows the total amount of compaction over three depth intervals $0-5 \mathrm{~m}$, 0-10 m, and 0-20 m, at three sites, Jurassic, Gomez, and Berkner Island. Figure 6 shows daily thinning rates obtained by differentiating these curves. These rates are differences between successive daily averages recorded by the position sensors. No other smoothing was applied. We have plotted the total thinning rate over each depth interval, rather than the strain rate, because this is the quantity most relevant to interpretation of radar altimeter observations. The strain rate can be recovered by dividing the thinning rates by $5 \mathrm{~m}, 10 \mathrm{~m}$ or $20 \mathrm{~m}$, as appropriate for each borehole. Although the total thinning rate is higher for the $20 \mathrm{~m}$ borehole, the average strain rate is lower. The data are overlain by curves showing modeled compaction rates computed using the following formula,

$$
d_{t} \rho= \begin{cases}c_{0}\left(\rho_{i}-\rho\right), & \rho<=550 \mathrm{~kg} \mathrm{~m}^{-3} \\ c_{1}\left(\rho_{i}-\rho\right), & \rho>550 \mathrm{~kg} \mathrm{~m}^{-3}\end{cases}
$$

in which $\rho_{i}=917 \mathrm{~kg} \mathrm{~m}^{-3}$ is the density of solid ice, and $c_{0}$, and $c_{1}$ are rate parameters whose values were defined using models of snow compaction from the literature [Herron and Langway, 1980; Li and Zwally, 2004; Helsen et al., 2008]. The models are described in more detail below. Different rate constants were used in each density range to allow for the enhancement in compaction caused by sliding of grains relative to each other.

[22] The total derivative $d_{t} \rho \equiv \partial_{t} \rho+v \partial_{z} \rho$ is the rate of change of density of a material parcel. To compute the modeled thinning rates, we integrated equation (1) numerically. The initial density $\rho_{0}$ for each section of the ice core was specified at the density measured for that section; the initial length $l_{0}$ of each section (roughly $10 \mathrm{~cm}$ ) was also recorded during core processing. To compute the change in length, we updated the density $\rho$ for each hourly time step using equation (1), and recomputed the length $l$, assuming mass conservation and vertical compression (i.e. $l=l_{0} \rho_{0} / \rho$ ). We computed the total amount of thinning from sections that originally spanned $0-5 \mathrm{~m}, 0-10 \mathrm{~m}$, and $0-20 \mathrm{~m}$ by summing the compaction $\left(l_{0}-l\right)$ over those sections. Curves show daily averages of the thinning rates in $\mathrm{mm} \mathrm{day}^{-1}$. 

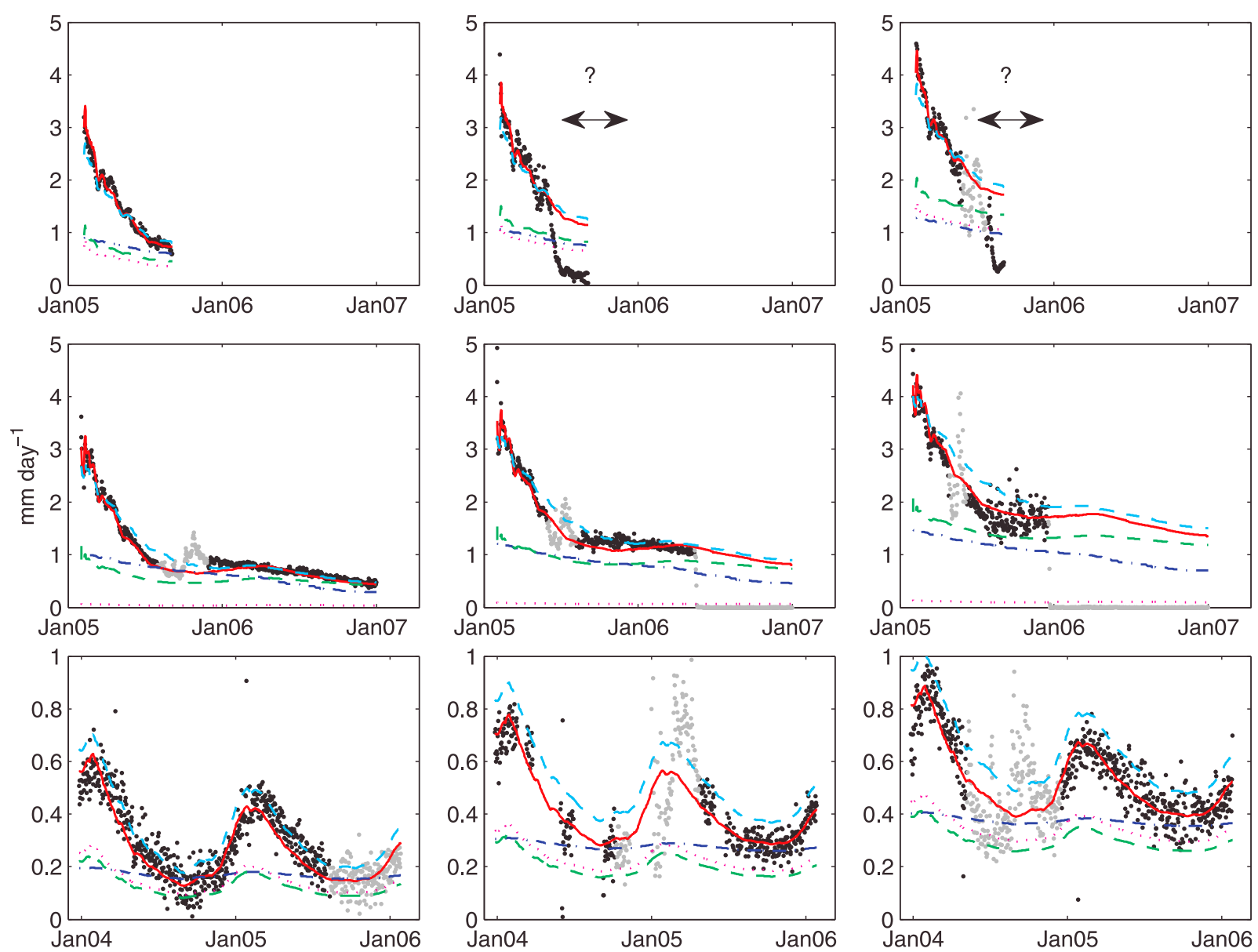

Figure 6. Thinning rates in $\mathrm{mm} \mathrm{day}^{-1}$ for different depth ranges: (left) $0-5 \mathrm{~m}$, (middle) $0-10 \mathrm{~m}$, and (right) 0-20 m, from three sites: (top) Jurassic, (middle) Gomez, and (bottom) Berkner Island. Dates are in monthyear format (e.g., Jan04 is January 2004). Curves show thinning rates predicted by various parameterizations of snow compaction: Herron and Langway [1980] (blue, dot-dashed); Li and Zwally [2004] (magenta, dotted); Helsen et al. [2008] (green, dashed); local 'best-fit' models used to derive parameters in Table 2 (red, solid); a semi-empirical model based upon rate equations for Nabarro-Herring creep and normal grain growth (cyan, dashed) (equation (4)).

[23] The rate parameters $c_{0}$, and $c_{1}$ in equation (1) were evaluated as follows, according to different models from the literature:

Herron and Langway [1980]

$$
\left\{\begin{array}{c}
c_{0}=11\left(\dot{b} / \rho_{w}\right) \exp \left[-\frac{10160}{R T}\right], \\
c_{1}=575 \sqrt{\dot{b} / \rho_{w}} \exp \left[-\frac{21400}{R T}\right]
\end{array}\right.
$$

Li and Zwally [2004]

$$
\left\{c_{0}=c_{1}=\left(\dot{b} / \rho_{i}\right)\left(139.21-0.542 T_{\mathrm{av}}\right) 8.36(273.15-T)^{-2.061}\right. \text {, }
$$

Helsen et al. [2008]

$\left\{c_{0}=c_{1}=\left(\dot{b} / \rho_{i}\right)\left(76.138-0.28965 T_{\mathrm{av}}\right) 8.36(273.15-T)^{-2.061}\right.$.

In these expressions, $\rho_{w}=1000 \mathrm{~kg} \mathrm{~m}^{-3}$ is the density of water and $R=8.314 \mathrm{~J} \mathrm{~mol}^{-1} \mathrm{~K}^{-1}$ is the gas constant. The mass accumulation rate $\dot{b}\left(\mathrm{~kg} \mathrm{~m}^{-2} \mathrm{yr}^{-1}\right)$ was taken from the shallow ice cores for Jurassic and Gomez, and from Mulvaney et al. [2002] for Berkner Island. The mean annual temperature
$T_{\text {av }}(\mathrm{K})$ was estimated at each site from the average temperature of the deepest thermistor, at approximately 10-m depth.

[24] The Herron and Langway [1980] parameterization was defined using steady state density profiles from Greenland and Antarctica, assuming an Arrhenius type temperature sensitivity for compaction. The Li and Zwally [2004] parameterization, which was originally informed by experiments on grain growth, has a different temperature sensitivity to the Herron and Langway [1980] model, and was further constrained by fits to steady state density profiles in Greenland. The Helsen et al. [2008] model was derived by modifying the Li and Zwally [2004] model, constraining it to match steady state profiles for Antarctic sites. Following Reeh [2008, equation 4], a simplified version of the $L i$ and Zwally [2004] and Helsen et al. [2008] models is used here.

[25] Estimates for the instantaneous temperature field $T(z, t)$ were provided by solving the one-dimensional heat conduction equation $\left(\rho c d_{t} T \equiv \rho c\left[\partial_{t} T+v \partial_{z} T\right]=\partial_{z}\left[\kappa \partial_{z} T\right]\right.$, with heat capacity $c=2009 \mathrm{~J} \mathrm{~kg}^{-1} \mathrm{~K}^{-1}$, and conductivity $\kappa=$ $\left.2.1\left(\rho / \rho_{i}\right)^{2} \mathrm{~W} \mathrm{~m}^{-1} \mathrm{~K}^{-1}\right)$, as described by Arthern and Wingham [1998]. The upper boundary condition for temperature was 
Table 2. Activation Energy and Rate Constants That Define the Best-Fit Model That Produced the Red Solid Curves Plotted in Figure $6^{\mathrm{a}}$

\begin{tabular}{lccccc}
\hline \multicolumn{1}{c}{ Site } & Activation Energy $E\left(\mathrm{~kJ} \mathrm{~mol}^{-1}\right)$ & $a_{0}\left(\mathrm{a}^{-1}\right)$ & $a_{1}\left(\mathrm{a}^{-1}\right)$ & Activation Energy $E^{*}\left(\mathrm{~kJ} \mathrm{~mol}^{-1}\right)$ & $a_{0}^{*}\left(\mathrm{a}^{-1}\right)$ \\
\hline Jurassic & 80 & $5.43 \times 10^{15}$ & $2.01 \times 10^{15}$ & 60 & $4.43 \times 10^{11}$ \\
Gomez & 120 & $3.86 \times 10^{23}$ & $1.79 \times 10^{23}$ & 60 & $1.48 \times 10^{11}$ \\
Berkner Island & 70 & $7.91 \times 10^{12}$ & $4.21 \times 10^{12}$ & 60 & $3.20 \times 10^{11}$ \\
\hline
\end{tabular}

${ }^{\mathrm{a}}$ The values $a_{0}^{*}$ and $a_{1}^{*}$ produce the best match when the activation energy is constrained to be $60 \mathrm{~kJ} \mathrm{~mol}^{-1}$.

specified from thermistors within the aluminum cases at the top of the borehole. For the lower boundary condition, the temperature of the deepest layer, at about 20-m depth, was set equal to $T_{\mathrm{av}}$. Temperatures were updated at each hourly time step, and used to recompute rate constants $c_{0}$, and $c_{1}$. We tested temperatures from the thermal model against thermistors at intermediate depths: these agreed within an r.m.s. error of $0.2 \mathrm{~K}$ at Jurassic and Gomez sites, and $0.7 \mathrm{~K}$ at the Berkner Island site.

[26] To further investigate the sensitivity of the compaction rate to temperature, we derived estimates of the activation energy $E$, by fitting a model of the form:

'Best-fit' $\quad\left\{\begin{array}{l}c_{0}=a_{0} \exp \left[-\frac{E}{R T}\right] \\ c_{1}=a_{1} \exp \left[-\frac{E}{R T}\right]\end{array}\right.$.

The parameters $a_{0}, a_{1}$ and $E$, were selected at each site to minimize the discrepancy with the observations of thinning. Details of this fitting procedure are given in Appendix A. The parameters that define the 'best-fit' model are shown in
Table 2 for each site. The red curves of Figure 6 show the corresponding time series. The r.m.s. errors of the best fits for the Jurassic, Gomez and Berkner sites are respectively 0.19 , 0.15 and $0.07 \mathrm{~mm} \mathrm{day}^{-1}$. Figure 7 illustrates the modeled temperature and strain rate of compaction in the upper ten meters at the Gomez site, based on the 'best-fit' model.

[27] A reasonable fit to the data can be made for other activation energies. Table 2 also lists $a_{0}^{*}$ and $a_{1}^{*}$, the values of $a_{0}$ and $a_{1}$ that give the best fit to our observations when the activation energy $E$ is constrained to be $60 \mathrm{~kJ} \mathrm{~mol}^{-1}$, a commonly used value for activation energy for ice deformation [Paterson, 1994]. Using these parameters, the r.m.s. errors for the Jurassic, Gomez and Berkner sites are respectively $0.21,0.19$ and $0.07 \mathrm{~mm}$ day $^{-1}$, not much worse than the minimum error values.

[28] Laboratory experiments have shown that there is an energy barrier of approximately $60 \mathrm{~kJ} \mathrm{~mol}^{-1}$ for molecular diffusion through the lattice of the ice crystal [Petrenko and Whitworth, 1999], so this is a potential mechanism that could explain our observations. Creep caused by lattice dif-

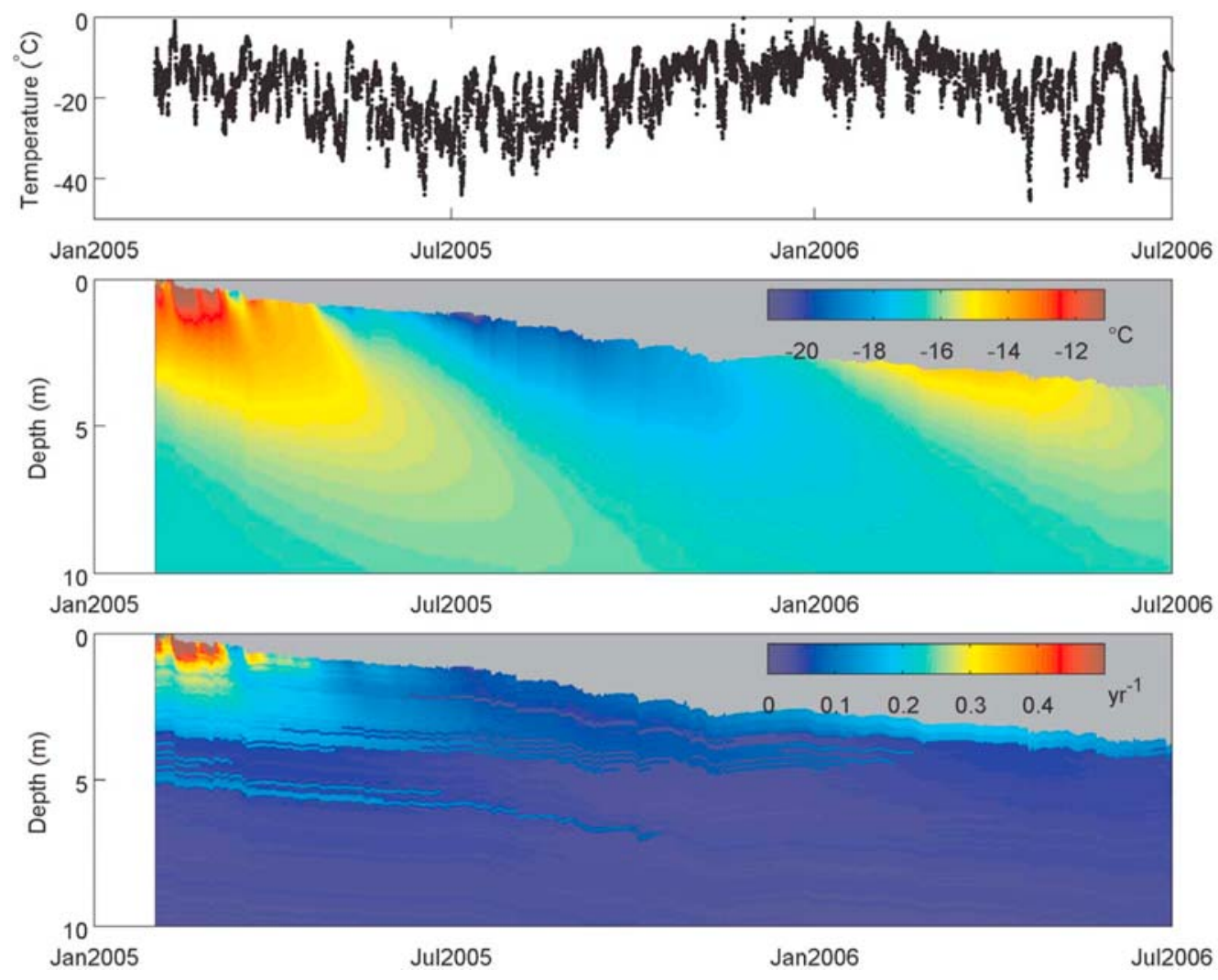

Figure 7. Temperature and snow accumulation at the Gomez Site: (top) air temperature $\left({ }^{\circ} \mathrm{C}\right)$, (middle) snow temperatures from the thermal model, (bottom) strain rates from the 'best fit' compaction model (see text). Gray shading represents fresh snow accumulation, as measured by the sonic depth rangers, and was not included in the model. 
Table 3. Thinning Rates Measured Over Various Depth Ranges From Physical Measurements ${ }^{\mathrm{a}}$

\begin{tabular}{lccccc}
\hline \multicolumn{1}{c}{ Site } & Start Date & End Date & $0-5 \mathrm{~m}\left(\mathrm{~mm} \mathrm{day}^{-1}\right)$ & $0-10 \mathrm{~m}\left(\mathrm{~mm} \mathrm{day}^{-1}\right)$ & $0-20 \mathrm{~m}\left(\mathrm{~mm} \mathrm{day}{ }^{-1}\right)$ \\
\hline Jurassic & 8 Feb 2005 & 21 Jan 2007 & $0.89(1.15)$ & $1.13(1.50)$ & $1.70(1.86)$ \\
Gomez & 1 Feb 2005 & 1 Jan 2007 & $0.940 .97^{\mathrm{b}}(1.11)$ & $1.34(1.71)$ & $1.76(2.14)$ \\
Berkner Island & 14 Feb 2003 & 27 Jan 2006 & $0.30^{\mathrm{b}}(0.16)$ & $0.46^{\mathrm{b}}(0.30)$ & $0.57^{\mathrm{b}}(0.38)$ \\
Dyer Plateau & 21 Jan 2005 & 8 Jan 2007 & $0.81(0.73)$ & $1.13(1.05)$ & $1.47(1.28)$ \\
\hline
\end{tabular}

${ }^{a}$ Values in brackets are predicted using Sorge's Law.

${ }^{\mathrm{b}}$ Thinning rates from automatic strainmeter.

fusion is known as Nabarro-Herring creep. Appendix B shows that by coupling rate equations for Nabarro-Herring creep [Coble, 1970] and normal grain-growth [Gow et al., 2004] a semi-empirical expression for the rate coefficients $c_{0}$ and $c_{1}$ can be obtained:

'Nabarro-Herring'

$$
\left\{\begin{array}{l}
c_{0}=0.07 \dot{b} g \exp \left(-E_{c} / R T+E_{g} / R T_{\mathrm{av}}\right) \\
c_{1}=0.03 \dot{b} g \exp \left(-E_{c} / R T+E_{g} / R T_{\mathrm{av}}\right)
\end{array} .\right.
$$

The coefficients 0.07 and 0.03 were determined empirically from $a_{0}^{*}$ and $a_{1}^{*}$ as described in Appendix B. Values of $60 \mathrm{~kJ}$ $\mathrm{mol}^{-1}$ for $E_{c}$, and $42.4 \mathrm{~kJ} \mathrm{~mol}^{-1}$ for $E_{g}$ were used to produce the cyan curves shown in Figure 6.

[29] At four sites, the total thinning in three depth intervals was recorded over at least two-years either from physical measurements or from the position transducer: the average rates are shown in Table 3, where they are compared with thinning rates predicted by Sorge's Law, i.e. $v\left(z_{1}\right)-v\left(z_{2}\right)=$ $\dot{b}\left(1 / \rho\left(z_{1}\right)-1 / \rho\left(z_{2}\right)\right)$. Densities for $0,5,10$ and $20 \mathrm{~m}$ were estimated from averages over the intervals $[0-1 \mathrm{~m}],[4.5-$ $5.5 \mathrm{~m}],[9.5-10.5 \mathrm{~m}]$, and [19-20 $\mathrm{m}]$ respectively.

\section{Discussion}

[30] The measured compaction rates are consistent with a slow viscous deformation of the snowpack. Strain rate decreases with depth, despite increasing load. Total thinning rates over $0-20 \mathrm{~m}$ are less than five $\mathrm{mm}$ day $^{-1}$ at all study sites, and agree with those predicted by Sorge's Law to within about $30 \%$ or $0.3 \mathrm{~mm}^{-1 a y}{ }^{-1}$. We characterized the observational error in our measurements using residuals from the best fit model and Monte-Carlo simulation: multiple simulations of the observational error were generated by fitting an autoregressive process to the residuals. These simulations suggest that thinning rates averaged over 2-years should be accurate to around $0.04 \mathrm{~mm}^{-1 a y}{ }^{-1}$; a similar accuracy is indicated by comparing the physical measurements and the electronically recorded data. The densities and accumulation rates used to compute thinning rates from Sorge's Law may be uncertain to about $10 \%$, perhaps more at the Berkner Island site where an earlier ice core was used. For a typical density profile, these uncertainties would compound to give more than $20 \%$ error in the thinning rates derived from Sorge's Law, so the differences in Table 3 are not highly significant. Compaction is faster at the Jurassic and Gomez Sites than at the Berkner Island site. This is because the snow is warmer, and the accumulation rates are higher, both of which promote faster compaction.

[31] There are fluctuations in the rate of compaction, but there is little evidence for sudden collapse of weak layers or naturally occurring 'firn quakes' within the snowpack at any of our sites. For a single day (21st March, 2004) the strainmeters at the Berkner Island site briefly recorded higher rates than shown in Figure 6, and then only at $2.4 \mathrm{~mm}_{\text {day }}{ }^{-1}$.

[32] A strong seasonal cycle is apparent in the rate of snow compaction at the Berkner Island site. This site has lower accumulation rate, so the strainmeters are buried less quickly, and sample two seasonal cycles at depths shallow enough to be strongly affected by the summer warming. The highest thinning rates at Berkner Island are in late January, in the austral summer, when the summer warmth has had time to conduct into the snowpack, as noted by Zwally and $L i$ [2002]. Thinning rates during the second year of the record are more muted, because seasonal warming is attenuated with depth. The amplitudes of the seasonal cycles are similar for $0-5 \mathrm{~m}$, $0-10 \mathrm{~m}$, and $0-20 \mathrm{~m}$, indicating that seasonal variations in compaction are largely confined to the upper $5 \mathrm{~m}$.

[33] At the Gomez site the influence of the summer warming in the second year is reduced, because the strainmeters were buried faster there than at Berkner Island. This effect masks the seasonal cycle at the higher accumulation sites. Figure 7 shows how the high burial rate at Gomez insulates the instrumented snow from summer warming in the second year, and how this affects the strain rates.

[34] At the Jurassic and Berkner Island sites, the three models from the literature compare reasonably well with the observations: thinning rates agree within a factor of three, and the fit becomes progressively better over time, as the snow sampled by the strainmeters is buried deeper. All three models underestimate the amplitude of the seasonal cycle in thinning rates at the Berkner Island site, which suggests they are not sufficiently sensitive to temperature. The $L i$ and Zwally [2004] and Helsen et al. [2008] models perform better in this respect than the Herron and Langway [1980] parameterization.

[35] As noted by Helsen et al. [2008], the parameterization of $L i$ and Zwally [2004] predicts non-physical, negative compaction rates for sites with mean annual temperature greater than $256.8 \mathrm{~K}$. The modification made to the Li and Zwally [2004] parameterization by Helsen et al. [2008] clearly improves the fit at the Gomez site, but even the modified formula predicts non-physical, negative compaction rates for mean annual temperature greater than $262.9 \mathrm{~K}$. As a separate issue, strong summer melting would become a serious concern for sites as warm as this [Reeh, 2008].

[36] Firn compaction can proceed via a number of different microphysical mechanisms [Wilkinson, 1988; Arthern and Wingham, 1998]. Nevertheless, under specified conditions one or other of these mechanisms will usually dominate [Maeno and Ebinuma, 1983]. For the two colder sites, the sensitivity of measured compaction rates to temperature is consistent with a dominant process that has an activation energy of around $70-80 \mathrm{~kJ} \mathrm{~mol}^{-1}$. 
[37] At the warmer Gomez site a larger activation energy of $120 \mathrm{~kJ} \mathrm{~mol}^{-1}$ gives a slightly better fit. Increased activation energy at warmer temperatures has been noted by Jacka and Li [1994] and Paterson [1994]. A different microphysical process may operate at such high temperatures. However, if we constrain the activation energy to be $60 \mathrm{~kJ} \mathrm{~mol}^{-1}$ (following Petrenko and Whitworth [1999]), the r.m.s. error increases by only about $0.04 \mathrm{~mm}$ day $^{-1}$, even at the Gomez site, so we cannot be certain that the mechanism of compaction there is different.

[38] In any event, our best estimates of the activation energy are considerably higher than other models of snow compaction [Kojima, 1964; Alley, 1987; Herron and Langway, 1980; Arthern and Wingham, 1998]. This supports the observation by Zwally and $L i$ [2002] that snow compaction is more sensitive to temperature than assumed by these earlier models. The disagreement between our observations and the very low value of around $10-20 \mathrm{~kJ} \mathrm{~mol}^{-1}$ derived by Herron and Langway [1980] is noteworthy, since the models are otherwise comparable. This discrepancy causes the Herron and Langway [1980] model to underestimate the seasonal changes (Figure 6).

[39] The higher activation energy that we recover indicates that the dominant mechanism has a relatively high energy barrier. Petrenko and Whitworth [1999] give a value of $60 \mathrm{~kJ}$ $\mathrm{mol}^{-1}$ for the activation energy of molecular diffusion within the ice lattice, comparable to the values recovered from our data, so this is a potential mechanism that could explain our observations. Appendix B describes a semi-empirical model derived by coupling rate equations for lattice-diffusion (Nabarro-Herring) creep and normal grain-growth [Gow et al., 2004; Burton, 1993]. This simple model can reproduce the low-density part of the Herron and Langway [1980] model, and explains its low temperature sensitivity.

[40] Comparing the coefficients recovered from the semiempirical model with laboratory data, we find that compaction of polar firn occurs faster than would be expected from a simple theory based on lattice diffusion creep around cylindrical pores. Possible reasons include experimental uncertainty in material parameters, errors introduced by our simple treatment of grain growth, oversimplification of geometric effects such as stress concentration within the necks between grains, dependence upon other details of the microstructure [Alley et al., 1982; Freitag et al., 2004; Fujita et al., 2009], or contributions from other densification mechanisms. Our simple model parameterizes grain rearrangement by enhancing the compaction rate at densities below $550 \mathrm{~kg} \mathrm{~m}^{-3}$. Alternatively, the granular rearrangement model of Alley [1987] could be tested against our data. Other mechanisms, such as grain-boundary diffusion creep [Coble, 1970; Colbeck, 1998], 'Harper-Dorn' [Kassner et al., 2007], or 'power law' dislocation creep [Wilkinson, 1988], may also contribute significantly. A separate analysis, similar to that presented here, would have to be performed for each candidate mechanism before unambiguously attributing the mechanism of sintering.

[41] The semi-empirical model, defined by equations (1) and (4) reproduces our observations fairly closely, and should prove useful in interpreting altimetry observations in coastal regions with temperature and accumulation rate comparable to our sites. Nevertheless, for the reasons discussed above, it may oversimplify the physics of compac- tion in polar firn, and should be tested further before being applied to other climatic regimes such as the cold interior of Antarctica.

[42] Although we have recovered many years of hourly strain data, the design of equipment could have been improved to increase the quantity and quality of data: battery failure and loose connections caused loss of data at the Berkner Island, Dyer Plateau, and Jurassic sites, and two of the position transducers at the latter site physically seized up.

[43] Experiments in such high accumulation risk complete burial with loss of data. The weather station masts were $5 \mathrm{~m}$ high, with approximately $4.5 \mathrm{~m}$ above the surface at time of installation. Gomez was buried a few centimeters beneath the surface after two years, but the equipment and data were recovered, based on a flow-corrected estimated position, using a ground penetrating radar. Only the wind vane of the Jurassic site was protruding at recovery. Satellite transmission of data, or taller masts, would lessen the risk of data loss.

[44] The quality of data was affected as the attachment point between bowstring and sensor wire passed around the pulley, and the end of travel was reached on some of the position transducers. Interference from the pulley could have been avoided by using a longer enclosure for the sensor cable. Pulleys could have been eliminated entirely by using vertical housings for the sensor cables, instead of the aluminum cases, although this would make the instruments more susceptible to disturbance by wind.

\section{Conclusions}

[45] We have presented a relatively simple and effective technique for the in situ measurement of snow compaction over periods of years. The histories of snow compaction rate were measured at sites in the Antarctic Peninsula and Berkner Island with snow accumulation ranging from 130 to $1040 \mathrm{~kg}$ $\mathrm{m}^{-2} \mathrm{a}^{-1}$, and mean annual temperature from -26 to $-17^{\circ} \mathrm{C}$. At these sites, the snow compacts steadily. No sudden failure or collapse in the upper twenty meters exceeded a few millimeters. For the most part, the rate of compaction changes slowly on seasonal, monthly and weekly timescales.

[46] The observed changes are described quite well by a simple model ([based upon that of Herron and Langway [1980]) with three adjustable parameters (one rate constant for low density, another for high, and an activation energy that determines the sensitivity to temperature). The amplitude and phasing of changes in compaction rate can be explained by coupling this simple model to a one-dimensional model of heat flow within the snowpack. This suggests that the observed changes in the rate of compaction were driven principally by seasonal and weather-related fluctuations in the temperature of the snow.

[47] Three models of snow compaction from the literature [Herron and Langway, 1980; Li and Zwally, 2004; Helsen et al., 2008] were compared with the measured rates. At the warmest site the model described by Li and Zwally [2004] predicts unrealistically low compaction rate. Elsewhere, the three models agree fairly closely, but they under-predict the amplitude of the seasonal cycle in compaction rate, mainly because they underestimate the compaction rate of nearsurface snow in summer. This suggests they are not sensitive enough to temperature. The modified version of the $L i$ and Zwally [2004] model described by Helsen et al. [2008] 

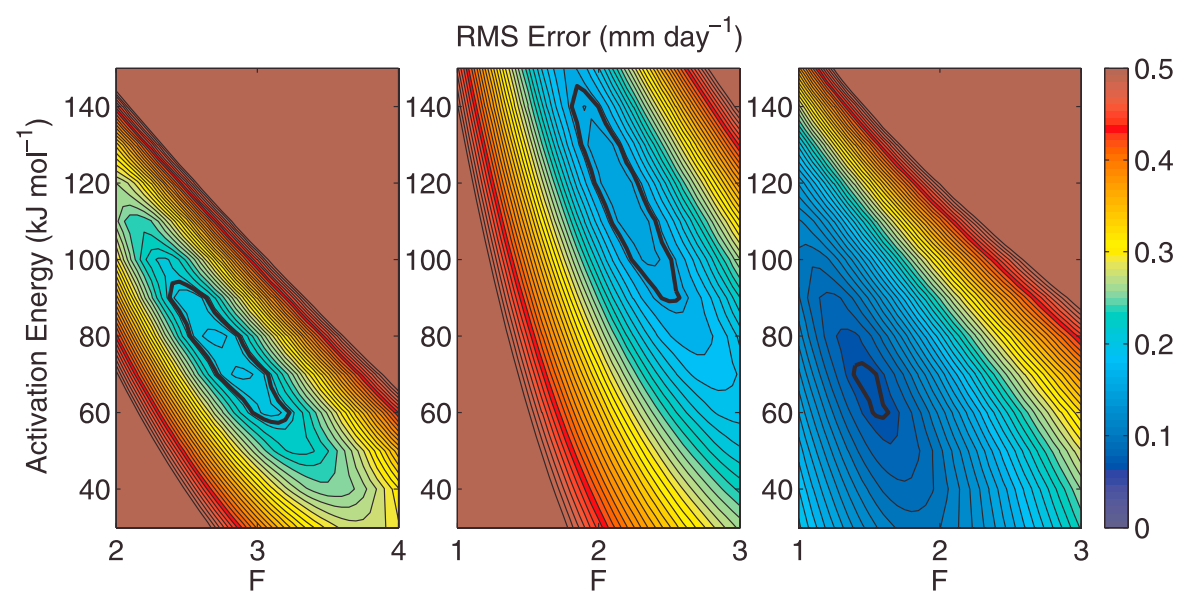

Figure A1. Selection of parameters for the 'best-fit' models. Contours show the root mean square disagreement between model and measured thinning rates $\left(\mathrm{mm} \mathrm{day}^{-1}\right)$ and how this changes as the Activation Energy $(E)$ and non-dimensional rate factor $(F)$ are varied. The contour interval is $0.01 \mathrm{~mm}^{-1}$. The com- $^{-1}$ parison was carried out over the range 0-5 m depth at three sites: (left) Jurassic, (middle) Gomez, and (right) Berkner Island. The parameters corresponding to the minimum error are listed in Table 2, and produce the red, solid curves on Figure 6.

seems to capture the seasonal cycle best overall, but the Herron and Langway [1980] model seems especially insensitive to temperature.

[48] The activation energies recovered from our simple model lie in the range $70-80 \mathrm{~kJ} \mathrm{~mol}^{-1}$ at the colder sites, and reach $120 \mathrm{~kJ} \mathrm{~mol}^{-1}$ at the warmest site, much larger than the value of $10-21 \mathrm{~kJ} \mathrm{~mol}^{-1}$ found by Herron and Langway [1980]. This apparent discrepancy can be reconciled if compaction occurs by grain-size dependent creep of material around pores, combined with normal grain-growth. Coupling rate equations for these processes reproduces the functional form of our simple model, and of the empirical Herron and Langway [1980] model, while explaining their different sensitivities to temperature. However, the molecular diffusivity inferred from our data is higher than published values, so we cannot unambiguously determine the mechanism of sintering.

\section{Appendix A: Parameter Estimation}

[49] To recover the parameters of the model defined by equation (3), simulations were performed for various combinations of $E, a_{0}$ and $a_{1}$. The best values were found by trialand-error comparison with the time series of compaction rate.

[50] The activation energy $E$ was varied in steps of $10 \mathrm{~kJ} \mathrm{~mol}^{-1}$ from 30 to $150 \mathrm{~kJ} \mathrm{~mol}^{-1}$. To provide an initial guess for the other parameters, we first derived a rough estimate $\widetilde{a_{1}}$ using the steady state assumption. Rearrangement of equation (1) gives

$$
d_{t}\left[-\ln \left(\rho_{i}-\rho\right)\right]=c_{1}, \quad \rho>550 \mathrm{~kg} \mathrm{~m}^{-3} .
$$

Assuming a steady state allows a rough estimate $\widetilde{c_{1}} \approx c_{1}$ to be derived from the slope of a plot of $-\ln \left(\rho_{i}-\rho\right)$ against time since deposition $t$ [cf. Herron and Langway, 1980]. Since the deeper snow is almost isothermal at the mean annual temperature $T_{\mathrm{av}}$, the approximation $\widetilde{a_{1}} \approx \widetilde{c_{1}} \exp \left(E / R T_{\mathrm{av}}\right)$ is obtained.
[51] Compaction is enhanced in the low density range, most likely from sliding of grains relative to each other [Alley, 1987], so $a_{0}>\widetilde{a_{1}}$ provides the best match. To search a reasonable span of values for $a_{0}$, we performed separate simulations using $a_{0}=F \widetilde{a_{1}}$, with each value of $F$ from 1 to 4 in steps of 0.05 . Figure A1 shows how the r.m.s. error varied with the choice of activation energy $E$ and non-dimensional rate factor $F$ for each site. The minima locate the parameter choices that define the 'best-fit' model at each site. The heavy contour indicates the minimum value plus two standard deviations of r.m.s. error, derived by fitting an autoregressive model to residuals from the best fit model, then using these to generate an ensemble for the r.m.s. error. This contour gives a rough indication of the range of parameter space that could be reached as a consequence of measurement errors and unmodeled fluctuations. As well as varying $a_{0}$ we tried combinations $a_{1}=0.8 \widetilde{a_{1}}, a_{1}=\widetilde{a_{1}}$, and $a_{1}=1.2 \widetilde{a_{1}}$ for the deeper, denser snow.

\section{Appendix B: A Semi-empirical Model for Snow Compaction}

[52] To derive the semi-empirical model (equation (4)) we combine an expression for creep in a medium with cylindrical pores [Wilkinson and Ashby, 1975, equation 20], with an expression for lattice-diffusion (Nabarro-Herring) creep of consolidated ice [Coble, 1970, equation 22] to give the densification rate:

$$
d_{t} \rho=k_{c}\left(\rho_{i}-\rho\right) \exp \left(-E_{c} / R T\right) \sigma / r^{2},
$$

with $r$ being grain radius, $\sigma$ the overburden pressure from snow loading, $E_{c}$ the activation energy for self-diffusion of water molecules through the ice lattice, and $k_{c}$ constant. Equation (B1) for the rate of Nabarro-Herring creep describes granular sliding, accommodated by molecular diffusion through the crystal lattice, across dimensions comparable to the grain size. Use of equation (B1) to represent granular 


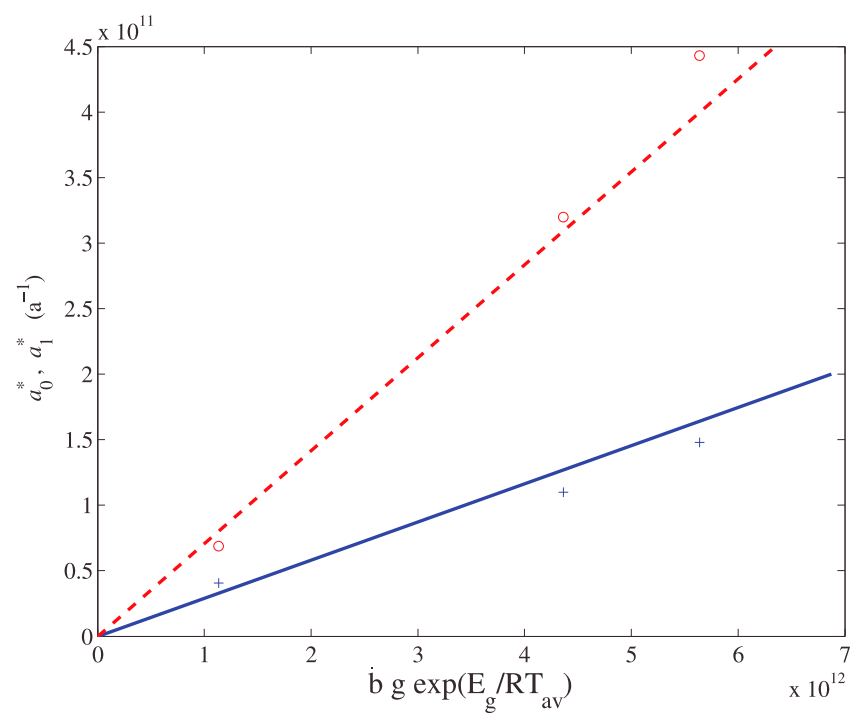

Figure B1. Parameterization of rate constants in terms of mean accumulation rate $\dot{b}$ and mean annual temperature $T_{\text {av }}$. Values from Table 2 are shown as $a_{0}^{*}$ (red circles) and $a_{1}^{*}$ (blue crosses) for the compaction of snow and firn with low $\left(\leq 550 \mathrm{~kg} \mathrm{~m}^{-3}\right)$ and high $\left(>550 \mathrm{~kg} \mathrm{~m}^{-3}\right)$ density respectively. The regression lines show $a_{0}^{*}=0.0709 \dot{b}$ gexp $\left(E_{g} / R T a v\right)$ (red dashed) and $a_{1}^{*}=0.0291 \dot{b} g \exp \left(E_{g} / R T_{\mathrm{av}}\right)$ (blue solid).

sliding assumes a jammed configuration of grains around the cylindrical pore, so that diffusion must occur before any sliding can take place [Onaka et al., 2001].

[53] A complete dynamical model would evolve the grainsize and snow-load as state variables, coupling equation (B1), with the heat-conduction, normal grain-growth and snowloading equations,

$$
\begin{aligned}
\rho c d_{t} T & =\partial_{z}\left[\kappa \partial_{z} T\right] \\
d_{t} r^{2} & =k_{g} \exp \left(-E_{g} / R T\right), \\
d_{t} \sigma & =\dot{b} g .
\end{aligned}
$$

Initial conditions $\rho=\rho_{0}, T=T_{0}, r^{2}=r_{0}^{2}$ and $\sigma=\sigma_{0}$, would then need to be specified for each snow parcel, along with upper and lower boundary conditions for temperature $T$.

[54] Rather than solve the full system of equations, we make some simplifying assumptions. For steady accumulation rate $\dot{b}$, and gravity $g$, the snow load can be approximated by $\sigma=\dot{b} g t$. Near the surface, fluctuations in temperature $T$ will affect the rate of grain growth in a non-linear way, and other effects such as temperature gradient metamorphism may occur; nevertheless, for simplicity, we assume that these effects can be neglected once the growth rate is integrated over sufficient time. Following Gow et al. [2004], we replace $T$ with the mean annual temperature $T_{\mathrm{av}}$ in the grain-growth equation and integrate to give,

$$
r^{2} \approx r_{s}^{2}+k_{g} \exp \left(-E_{g} / R T_{\mathrm{av}}\right) t
$$

with $r_{s}$ the initial surface value, $k_{g}$ a constant and $E_{g}$ the activation energy for grain growth. For small initial grain size, after sufficient time, $r^{2} \approx k_{g} \exp \left(-E_{g} / R T a v\right) t$. Combined with equation (B1), this gives an approximate expression for the densification rate,

$$
d_{t} \rho \approx\left(\dot{b} g k_{c} / k_{g}\right)\left(\rho_{i}-\rho\right) \exp \left(-E_{c} / R T+E_{g} / R T_{\mathrm{av}}\right)
$$

Equation (B4) has the same form as the 'best-fit' models defined by equations (2) and (3). Assuming a value of $60 \mathrm{~kJ}$ $\mathrm{mol}^{-1}$ for $E_{c}$, and $42.4 \mathrm{~kJ} \mathrm{~mol}^{-1}$ for $E_{g}$ (following Paterson [1994]), the ratio $k_{c} / k_{g}$ can be estimated for high and low density ranges from a plot of $\dot{b} g \exp \left(E_{g} / R T_{\text {av }}\right)$ against $a_{0}^{*}$ and $a_{1}^{*}$, using values from Table 2 . The gradients of the regression lines (Figure B1) provide an estimate of $k_{c} / k_{g}=0.0709 \mathrm{~m} \mathrm{~s}^{2}$ $\mathrm{kg}^{-1}$ for low density snow and $0.0291 \mathrm{~m} \mathrm{~s}^{2} \mathrm{~kg}^{-1}$ for high density snow. These values were used to define the semiempirical model, equation (4). The predictions made using this model are shown in Figure 6.

[55] Assuming spherical grains with average crosssectional area $2 \pi r^{2} / 3$, data provided by Paterson [1994] can be used to estimate the grain growth coefficient as $k_{g} \approx 1.3 \times$ $10^{-7} \mathrm{~m}^{2} \mathrm{~s}^{-1}$. Thus, we obtain estimates of the creep coefficients $k_{c} \approx 9.2 \times 10^{-9} \mathrm{~kg}^{-1} \mathrm{~m}^{3} \mathrm{~s}$ and $k_{c} \approx 3.7 \times 10^{-9} \mathrm{~kg}^{-1} \mathrm{~m}^{3} \mathrm{~s}$ for low and high density snow respectively.

[56] The remaining question is how closely the values of $k_{c}$ recovered from our data agree with experimental values for the rate of molecular diffusion in ice. According to Coble [1970] and Wilkinson [1988], we expect $k_{c} \approx 13 \Omega D_{0} / k_{B} T$ with molecular volume $\Omega=3.6 \times 10^{-29} \mathrm{~m}^{3}, k_{B}=1.38 \times$ $10^{-23} \mathrm{~J} \mathrm{~K}^{-1}$, and $D_{0}=0.0011 \mathrm{~m}^{2} \mathrm{~s}^{-1}$ [Petrenko and Whitworth, 1999]. These values provide a laboratory-based estimate $k_{c} \approx 1.6 \times 10^{-10} \mathrm{~kg}^{-1} \mathrm{~m}^{3} \mathrm{~s}$. Our values of $k_{c}$ for high and low density snow are respectively 20 , and 60 times higher than this estimate.

[57] Equation (B4) has the same form as the low-density part of the Herron and Langway [1980] parameterization, and can explain its low sensitivity to temperature. When considering different sites, snow deep enough to be insulated from seasonal changes has $T \approx T_{\text {av }}$, so the exponential term can be approximated as $\exp \left(-\left(E_{c}-E_{g}\right) / R T_{\text {av }}\right)$. To reproduce the low density part of the Herron and Langway [1980] model with $E_{c}=60 \mathrm{~kJ} \mathrm{~mol}^{-1}$ would require $k_{c} / k_{g}=1.1 \times 10^{-3} \mathrm{~m} \mathrm{~s}^{2} \mathrm{~kg}^{-1}$, and $E_{g}=49.8 \mathrm{~kJ} \mathrm{~mol}^{-1}$. Adjusting $k_{g}=6.3 \times 10^{-6} \mathrm{~m}^{2} \mathrm{~s}^{-1}$ to match grain growth data of Paterson [1994] for this revised activation energy, gives a value of $k_{c} \approx 6.9 \times 10^{-9} \mathrm{~kg}^{-1} \mathrm{~m}^{3} \mathrm{~s}$, around 40 times higher than the laboratory-based estimate.

[58] Our use of equation (B3) is an approximation. If departures of temperature $T$ from the average $T_{\mathrm{av}}$ are large enough, or persist for long enough, it would be more accurate to derive the grain size by solving the coupled system B2.

[59] Acknowledgments. We would like to thank Dougal Ranford, Andrew Barker and Neil Farnell, for invaluable assistance in the field. Thanks to all at British Antarctic Survey operations for logistic support, to Phil Anderson, Russ Ladkin and Cathy Moore for weather station support, to Keith Nicholls for logger software, Triona McGrath for ice core chemical analyses, and Gordon Hamilton for helpful advice. The research was funded under the Natural Environment Research Council, Antarctic Funding Initiative.

\section{References}

Alley, R. (1987), Firn densification by grain-boundary sliding: A 1st model, J. Phys., 48(C-1), 249-256. 
Alley, R. B., J. F. Bolzan, and I. M. Whillans (1982), Polar firn densification and grain growth, Ann. Glaciol., 3, 7-11.

Arthern, R., and D. Wingham (1998), The natural fluctuations of firn densification and their effect on the geodetic determination of ice sheet mass balance, Clim. Change, 40(3-4), 605-624.

Bader, H. (1960), Theory of densification of snow on high polar glaciers 1, Tech. Rep. 69, Cold Reg. Res. and Eng. Lab., Hanover, N. H.

Bader, H. (1962), Theory of densification of snow on high polar glaciers 2, Tech. Rep. 108, Cold Reg. Res. and Eng. Lab., Hanover, N. H.

Barnola, J., P. Pimienta, D. Raynaud, and Y. Korotkevich (1991), CO2Climate relationship as deduced from the Vostok ice core: A reexamination based on new measurements and on a reevaluation of the air dating, Tellus Ser. B, 43(2), 83-90.

Blackford, J. R. (2007), Sintering and microstructure of ice: A review, J. Phys. D Appl. Phys., 40(21), R355-R385, doi:10.1088/0022-3727/ 40/21/R02.

Braithwaite, R., M. Laternser, and W. Pfeffer (1994), Variations of nearsurface firn density in the lower accumulation area of the Greenland ice-sheet, Pakitsoq, West Greenland, J. Glaciol., 40(136), 477-485.

Burton, B. (1993), A theoretical upper limit to Coble creep strain resulting from concurrent grain-growth, J. Mater. Sci., 28(18), 4900-4903.

Coble, R. (1970), Diffusion models for hot pressing with surface energy and pressure effects as driving forces, J. Appl. Phys., 41(12), 4798.

Colbeck, S. (1998), Sintering in a dry snow cover, J. Appl. Phys., 84(8), 4585-4589.

Dibb, J., and M. Fahnestock (2004), Snow accumulation, surface height change, and firn densification at Summit, Greenland: Insights from 2 years of in situ observation, J. Geophys. Res., 109, D24113, doi:10.1029/2003JD004300.

Freitag, J., F. Wilhelms, and S. Kipfstuhl (2004), Microstructure-dependent densification of polar firn derived from X-ray microtomography, J. Glaciol., 50(169), 243-250.

Fujita, S., J. Okuyama, A. Hori, and T. Hondoh (2009), Metamorphism of stratified firn at Dome Fuji, Antarctica: A mechanism for local insolation modulation of gas transport conditions during bubble close off, J. Geophys. Res., 114, F03023, doi:10.1029/2008JF001143.

Gerland, S., H. Oerter, J. Kippstuhl, F. Wilhelms, H. Miller, and W. Miners (1999), Density log of a $181 \mathrm{~m}$ long ice core from Berkner Island, Antarctica, Ann. Glaciol., 29, 215-219.

Gow, A., D. Meese, and R. Bialas (2004), Accumulation variability, density profiles and crystal growth trends in ITASE firn and ice cores from West Antarctica, Ann. Glaciol., 39, 101-109.

Gray, J., and L. Morland (1995), The compaction of polar snow packs, Cold Reg. Sci. Technol., 23(2), 109-119.

Hamilton, G., I. Whillans, and P. Morgan (1998), First point measurements of ice-sheet thickness change in Antarctica, Ann. Glaciol., 27, 125-129.

Helsen, M., M. van den Broeke, R. van de Wal, W. van de Berg, E. van Meijgaard, C. Davis, Y. Li, and I. Goodwin (2008), Elevation changes in Antarctica mainly determined by accumulation variability, Science, 320(5883), 1626-1629, doi:10.1126/science.1153894.

Herron, M. M., and C. C. Langway (1980), Firn densification: An empiricalmodel, J. Glaciol., 25(93), 373-385.
Jacka, T., and J. Li (1994), The steady-state crystal size of deforming ice, Ann. Glaciol., 20, 13-18.

Kassner, M. E., P. Kumar, and W. Blum (2007), Harper-Dorn creep, Int. J. Plast., 23(6), 980-1000, doi:10.1016/j.ijplas.2006.10.006.

Kojima, K. (1964), Densification of snow in Antarctica, in Antarctic Snow and Ice Studies, Antarc. Res. Ser., vol. 2, edited by M. Mellor, pp. 157-218, AGU, Washington, D. C.

Kotlyakov, V. M. (1961), The Snow Cover of the Antarctic and Its Role in the Preset-Day Glaciation of the Continent (in Russian), Izdatel'stvo Akademii Nauk SSSR, Moskva, English translation, Isr. Program for Sci. Transl., Jerusalem, 1966.

Li, J., and H. Zwally (2004), Modeling the density variation in the shallow firn layer, Ann. Glaciol., 38, 309-313.

Maeno, N., and T. Ebinuma (1983), Pressure sintering of ice and its implication to the densification of snow at polar glaciers and ice sheets, J. Phys. Chem., 87(21), 4103-4110.

McConnell, J., R. Arthern, E. Mosley-Thompson, C. Davis, R. Bales, R. Thomas, J. Burkhart, and J. Kyne (2000), Changes in Greenland ice sheet elevation attributed primarily to snow accumulation variability, Nature, 406(6798), 877-879.

Mulvaney, R., H. Oerter, D. Peel, W. Graf, C. Arrowsmith, E. Pasteur, B. Knight, G. Littot, and W. Miners (2002), 1000 year ice-core records from Berkner Island, Antarctica, Ann. Glaciol., 35, 45-51.

Onaka, S., A. Madgwick, and T. Mori (2001), Kinetics of diffusional creep discussed by energy dissipation and effect of grain-size distribution on the rate equations, Acta Mater., 49(12), 2161-2168.

Paterson, W. (1994), Physics of Glaciers, 3rd ed., Pergamon, Oxford, U. K. Petrenko, V. F., and R. W. Whitworth (1999), Physics of Ice, Oxford Univ. Press, New York.

Reeh, N. (2008), A nonsteady-state firn-densification model for the percolation zone of a glacier, J. Geophys. Res., 113, F03023, doi:10.1029/ 2007JF000746.

Spencer, M., R. Alley, and T. Creyts (2001), Preliminary firn-densification model with 38-site dataset, J. Glaciol., 47(159), 671-676.

Wilkinson, D. (1988), A pressure sintering model for densification of polar firn and glacier ice, J. Glaciol., 34, 40-45.

Wilkinson, D., and M. Ashby (1975), Pressure sintering by power law creep, Acta Metall., 23(11), 1277-1285.

Wingham, D. (2000), Small fluctuations in the density and thickness of a dry firn column, J. Glaciol., 46(154), 399-411.

Zwally, H., and J. Li (2002), Seasonal and interannual variations of firn densification and ice-sheet surface elevation at the Greenland summit, J. Glaciol., 48(161), 199-207.

Zwally, H. J., M. B. Giovinetto, J. Li, H. G. Cornejo, M. A. Beckley, A. C. Brenner, J. L. Saba, and D. Yi (2005), Mass changes of the Greenland and Antarctic ice sheets and shelves and contributions to sea-level rise: 1992-2002, J. Glaciol., 51(175), 509-527.

R. J. Arthern, R. Mulvaney, A. M. Rankin, E. R. Thomas, and D. G. Vaughan, British Antarctic Survey, Natural Environment Research Council, High Cross, Madingley Rd., Cambridge CB3 0ET, UK. (rart@ bas.ac.uk) 